$=10^{-3} \mathrm{~kg} \mathrm{~mol}^{-1}$ ), will continue in use as an accepted decimal sub-multiple of the SI unit. However, the SI unit itself is suitable for expressing values of the molar mass for macromolecular substances. Thus, one could add to Dr Edsall's equivalent statements the alternative : "the molar mass of protein $\mathrm{X}$ is $25 \mathrm{~kg}$ $\mathrm{mol}^{-1}$ ".

Although the unit of mass, "unified atomic mass unit", is outside the SI, it has been recognized by the CIPM as useful in specialized fields of scientific research ${ }^{1}$. Its value expressed in the SI unit, the kilogram, is derived by experiment and is therefore not known exactly. Although in general one should be chary of proliferating special names, the present name for this unit, even when contracted to "atomic mass unit" (the term "unified" distinguishing it from slightly different earlier units based on ${ }^{16} \mathrm{O}$ and on $\mathrm{O}=16$ ), is not notably convenient or informative. Dr Edsall's suggestion that it be renamed the dalton merits consideration by the international agencies concerned with standardization of chemical and physical nomenclature so long as the unit itself continues to be recognized by the CIPM as one of those useful outside the SI in specialized fields. It would not be helpful if scientists in different fields employed different names for the same unit.

Yours faithfully,

Martin A. Paul

Division of Chemistry and

Chemical Technology,

National Academy of Sciences-

National Research Council,

Washington, DC 20418, USA

1 The International System of Units (SI), translation approved by the International Bureau of Weights and Measures of its publication, Le Système International d'Unités, prepared jointly and published independently by the National Physical Laboratory, UK, and the National Bureau of Standards, USA: National Bureau of Standards Special Publication 330, 1970, US Government Printing Office, Washington, DC 20402.

\section{Definition of Intelligence}

SIR,--Because others (Nature, 228, 1008; 1970) have commented on the definition of intelligence put forward by Fatmi and Young (Nature, 228, 97; 1970) and subsequently extended by myself (Nature, 228, 589; 1970), I would like to make some further observations.

With regard to the letter from P. M. Muller, the process of induction would be covered by my own definition, as would "synthetic a priori". However, processes of reasoning from the part to the whole, from the particular to the general, and from the individual to the universal, are not identical and isomorphic processes, nor are they symmetrical with respect to deduction and induction.

If we accept Gödel's theorem, a single, finite automaton with a phrase-structure grammar can be either complete and consistent (closed) or universal (open). A Gödel complete system will accept only tautologies or empirically verifiable sensedata that have been specified in the instruction set, rejecting all other inputs as illogicality or "noise". The possibility of new or unspecified states is excluded. If we assume that human intelligence not only construes syllogisms, but also discovers, elucidates and initiates the previously unknown, then it is clear that this cannot be a property of Gödel complete automata (existing computers). Indeed, it would seem that an incomplete instruction set (a quasi-nondeterministic system) is a necessary condition for the emergence and evolution of intelligence, as we observe it in living systems. However, the possibilities of machines do not end with single finitestate machines or with phrase-structure grammars.

In my own work I have been considering the possibilities of hierarchical networks of automata, some of them backward deterministic ${ }^{1}$, in an attempt to solve the Gödel theorem problem for quasi-non-deterministic systems, including brain-models. The basic idea is to axiomatize the levels of the system independently and use negative feedback to control the universality (requisite variety) of both individual levels and the system as a whole. An essential part of the control system is an order : disorder detector, as suggested by $\mathbf{H}$. B. Barlow in his letter. This type of system would also imply that the original definition of Fatmi and Young would be too broad to draw a valid distinction between men and machines.

With regard to the letter from $H$. A. Cook. Any system is quantifiable if one knows what to measure and how to measure it. It is another matter to decide whether such a quantification provides an adequate description of the system as a whole. The informationtheoretic brain model mentioned above implies a physiological symbol-processing mechanism in the brain, which could form a substrate for the heritable components of both intelligence and linguistic behaviour. Since such a component would be determined by input-rate and digitspan, and would be invariant with respect to learning, it should be possible to isolate and quantify it given a calibrated digital input and criteria for assessing the output response in quantitative terms. With regard to a quantified definition of intelligence, without recourse to linguistic behaviour, we may be up against a special case of Richard's paradox.

The correspondence following Fatmi and Young's original letter has emphasized the need for further dialogue concerning the theoretical and philosophical aspects of machine and human intelligence, and it is gratifying to learn that the Cambridge Branch of the Brain Research Association is setting up a forum in this area of study.

\section{Yours faithfully, GORDON HYDE}

11 The Close,

Dunmow, Essex CM6 $1 \mathrm{EW}$

1 Wang How, $A$ Survey of Mathematical Logic, 175 (North-Holland, 1964).

\section{Obituary}

\section{Dr J. E. Falk}

JoHN EDWIN FALK, chief of the division of plant industry, Commonwealth Scientific and Industrial Research Organization, Canberra, died on October 25, 1970. Born in 1917 at Cessnock, NSW, he studied pharmacy at the University of Sydney, but finding that his interests lay in chemistry he completed a Bachelor of Science degree in 1942. After graduating he joined Professor V. M. Trikojus in an investigation of synthetic methods of preparation of essential drugs unavailable in war time Australia. In 1944 he became Chief Chemist at Bayer's in Sydney and at the end of the war returned to research in the university on a Wellcome fellowship under Professor Adrian Albert. During this period his research into the mode of action of certain antimalarial drugs awakened his interest in biochemistry and led him into the field of haem pigments. In 1947 he was awarded a grant by the National Health and Medical Research Council to work at the Royal North Shore Hospital, Sydney, under Professor M. R. Lemberg, FRS. Here he investigated the prosthetic group of cytochrome oxidase and learnt a great deal about porphyrins.

In 1948, Falk was granted a Nuffield travelling fellowship and with financial assistance from the National Health and Medical Research Council he went to University College Hospital Medical School in London to work with Professor C. Rimington, FRS. His research included a systematic study of the infrared spectra of porphyrins and haems as well as further work on cytochrome oxidase. He received his $\mathrm{PhD}$ in 1951. A "Nuffield Unit of Pyrrole Pigment Research" was established in Professor Rimington's department and Falk was appointed director. In 1953, he was awarded a Foulerton research fellowship by the Royal Society. During this period, he developed analytical methods for porphyrins and turned his attention 
to the biosynthesis of porphyrins and haems.

His contact with Professor R. S. (now Sir Ronald) Nyholm, FRS, of the Department of Chemistry, University College, led to his interest in the coordination chemistry of porphyrins and metalloporphyrins. Much of his later research was concerned with an attempt to understand the spectral and biological properties of haemoproteins in terms of their coordination and physical chemistry.

In 1955 he returned to Australia and joined CSIRO as head of the biochemistry section of the Division of Plant
Industry. He was elected a Fellow of the Australian Academy of Science in 1961 and was president of the Australian Biochemical Society from 1964-66. In 1963 he succeeded Sir Otto Frankel, FRS, as chief of the largest division of CSIRO, and one of the major agricultural research institutions in the world. $\mathrm{He}$ devoted much effort to building bridges between the research of his division and the worlds of the farmer, the economist and the extension worker while maintaining the scientific excellence of the institution. He played an active part in discussions on defining a govern- ment science policy and in developments in the social role of science.

Falk retained his own research interests and his book Porphyrins and Metalloporphyrins, published in 1964, reflects in the clarity and conciseness of its presentation his ability as a writer. $\mathrm{He}$ was an excellent flautist and played for many orchestras including the Sydney Symphony Orchestra; he did much to encourage musical activities in Canberra. A distinguished scientist and outstanding organizer, John Falk was also a warm hearted and generous friend. $\mathrm{He}$ will be sadly missed.

\section{Announcements}

\section{New Year Honours}

The following honours awards were announced on January 1 : Knight Bachelor, Professor F. S. Dainton, for services to science and higher education; Dr G. E. R. Deacon, director of the National Institute of Oceanography; Wylie McKissock, neurological surgeon; CBE, Professor F. K. Bannister, University of Birmingham; Eric S. Booth, Central Electricity Generating Board; Professor J. G. D. Clark, University of Cambridge; Professor A. I. Darling, University of Bristol ; Professor J. L. Gowans, for services to medical science; C. Joliffe, Science Research Council; W. Marsh, Rolls-Royce, Derby; Professor J. Walker, University of Dundee; D. J. Watson, Rothamsted Experimental Station; Professor A. Wilson, University of Liverpool; OBE, R.J. Adle, British Antarctic Survey; G. S. Innes, St Bartholomew's Hospital, London; E. I. Lloyd, Ministry of Aviation Supply; Professor A. L. Roberts, University of Leeds; J. S. M. Robertson, Western Regional Hospital Board (Scotland); S. J. Robinson, Mullard Research Laboratories, Redhill.

\section{University News}

Dr Arthur F. Turner, head of the optical Physics Department, Vacuum Coating Division, Bausch and Lomb Inc., has been appointed professor of optical sciences in the University of Arizona.

Dr R. H. Ottewill has been appointed to the chair of colloid science in the School of Chemistry, University of Bristol.

Dr Sven Paulin has been appointed professor of radiology at Harvard University and radiologist-in-chief at the Beth Israel Hospital, Boston.

Professor P. T. Matthews has been appointed head of the Department of Physics, Imperial College, University of
London, in succession to Professor C. C. Butler, on whom the title of professor of physics has been conferred. The title of professor of chemistry has been conferred on Dr Mary R. Truter in respect of her post at University College, London.

Mr Aron Holzel has been appointed to an additional chair of child health in the University of Manchester.

Dr William Anderson has been appointed to the chair of pharmaceutical technology in the University of Strathclyde.

\section{Appointments}

Mr George W. Cherry has been appointed director of the Aeronautical Operating Systems Division in the Office of Advanced Research and Technology, NASA.

Dr Byron Riegel, director of chemical research at G. D. Searle and Company, has been elected 1971 chairman of the board of directors of the American Chemical Society in succession to Dr Milton Harris.

Professor A. L. Hodgkin, president of the Royal Society, and Professor P. B. Hirsch, professor of metallurgy in the University of Oxford, have been appointed members of the Council for Scientific Policy, in place of Lord Blackett and Dr C. E. Lucas.

\section{Miscellaneous}

Mr Charles P. Ginsburg, vice president (advanced development) for the Ampex Corporation and Professor Erwin W. Mueller, Pennsylvania State University, have each been awarded a John Scott medal and a cash award of $\$ 2,000$ for their work in videotape recording and field-ion microscopy respectively.

The 1970 MacRobert award for engineering and technology has been presented to H. R. Warman, A.N. Thomas and Dr P. E. Kent, geologists with British Petroleum, for their geological and geophysical survey work in Alaska which led to the discovery of the North Slop oilfields.

Nominations for the 1972 Roussel prize for outstanding work in the field of steroids are invited. The prize is worth $\$ 6,000$ and candidates may be of any nationality. Further information can be obtained from the secretary of the award committee, Professor J. Mathieu, Centre de Recherches, Roussel-Uclaf, 93 Romainville, France.

Applications are invited for the Perkin centenary scholarships and Perkin travel grants. The scholarships are intended to enable employees of industrial firms concerned with the manufacture or application of colouring materials to study at a university or technical college. The travel grants are available for teachers concerned with any aspect of the manufacture or applications of colouring matters to visit to gain experience in institutions other than their own. Further information and forms of application can be obtained from the secretary of the Perkin Centenary Trust, c/o The Chemical Society, Burlington House, London W1.

The New York Cancer Research Institute has established a number of fellowships for the support of qualified individuals who wish to receive training and experience in experimental or clinical cancer immunology. Applicants may be of any nationality and should hold an $\mathrm{MD}$ or $\mathrm{PhD}$ degree. The value of each fellowship will vary according to the experience and responsibility of the applicant. Further information can be obtained from Mrs W. B. Nauts, executive director, New York Cancer Research Institute Inc., 1225 Park Avenue, New York, NY 10028, USA.

ERRATUM. In the review "Derivatives of NH" by P. Sykes (Nature, 228, 1233; 1970), the first sentence in the second paragraph should read "There has in the past been some confusion over the naming of nitrenes, but the use of the definition in the first paragraph ...". 